\title{
Current status of lung transplantation
}

\author{
C.L. Lau, G.A. Patterson
}

Current status of lung transplantation. C.L. Lau, G.A. Patterson. (C) ERS Journals Ltd 2003.

ABSTRACT: Two decades have passed since the first successful clinical lung transplant was performed in 1983, and, in the interim, lung transplantation has become the preferred treatment option for a variety of end-stage pulmonary diseases. Remarkable progress has been made in the field through refinement of technique and improved understanding of transplant immunology and microbiology.

Unfortunately, donor shortages continue to limit the more widespread application of lung transplantation. In order to address this issue, marginal donors, living lobar and split lung donor techniques, and nonheartbeating donors have been used clinically to increase the number of donor lungs available.

Chronic rejection of the lung allograft is currently the major hurdle limiting longterm survival. To date, prevention of known risk factors and treatment strategies have not lessened the devastating toll this process has on lung transplant survival. Better understanding of the cause of chronic rejection is needed in order to develop novel strategies for its treatment. Promotion of immune tolerance is a promising area that could potentially eliminate chronic rejection.

The present article discusses recent advances in lung transplantation. It also details the major issues facing the field today. Only through continued clinical and experimental investigation will lung transplantation eventually reach its full potential. Eur Respir J 2003; 22: Suppl. 47, 57s-64s.
Division of Cardiothoracic Surgery, Washington University School of Medicine, St Louis, MO, USA.

Correspondence: G.A. Patterson

Suite 3108, Queeny Tower

P.O. Box 8234

St Louis, MO63110

USA

Fax: 13143620328

E-mail: lauch@msnotes.wustl.edu

Keywords: Bronchiolitis obliterans syndrome donor selection

lung transplantation

reperfusion injury

Received: February 282003

Accepted after revision: April 282003
It has been almost 20 yrs since the first successful clinical lung transplant was performed by the Toronto Group in 1983 [1]. Remarkable progress has been achieved since then. A number of programmes have accrued major experience and devised new approaches which have improved overall results. Approximately 1,400 transplants are performed worldwide each year. The International Society for Heart and Lung Transplantation (ISHLT) Registry lists $>14,500$ lung transplant recipients in its database [2]. For experienced programmes, operative mortality rates are $<10 \%$ and $1-\mathrm{yr}$ survival is $>80 \%$ for most diagnoses [3]. Functional results are excellent and durable. Post-transplant quality-of-life studies demonstrate significant improvement in the majority of patients [4-10]. There are a number of problems which compromise the results and outcome for potential recipients and those who have already received transplants. The biggest problem is a lack of suitable donors. This results in a longer recipient waiting time and increased death rates on the waiting list, especially for patients with pulmonary fibrosis and cystic fibrosis [11-14]. These long waiting times have forced transplant programmes to relax previously stringent donor selection criteria in an effort to secure more donor lungs. Improvements in lung preservation strategies have reduced the incidence of serious reperfusion injury, but this acute lung injury still occurs unpredictably, resulting in increased duration of intensive care unit stay, morbidity and mortality. Chronic lung allograft dysfunction or bronchiolitis obliterans syndrome (BOS) represents the most common cause of late post-transplant mortality. Initially, it was presumed that BOS was principally due to alloimmune mechanisms and represented chronic graft rejection. This may be only part of the explanation as recent data suggest that nonalloimmune mechanisms probably play a role in pathogenesis. Long-term success will only become possible when there is better understanding of the cause of BOS and better strategies for its treatment.

\section{Current indications}

The majority of adult lung transplants are performed for the following conditions: emphysema due to chronic obstructive pulmonary disease or $\alpha_{1}$-antitrypsin deficiency, cystic fibrosis, and pulmonary fibrosis $[2,15]$. With the widespread successful use of intravenous prostacyclin [16], pulmonary hypertension is now an uncommon indication for lung transplantation in North America. A wide variety of miscellaneous conditions comprise $<10 \%$ of lung transplant experience [2]. The relative frequency of lung transplant for the major conditions varies from programme to programme and country to country. In the ISHLT Registry, obstructive lung disease represents the most common indication in the adult population [2]. In the adult lung transplant programme at Barnes-Jewish Hospital (St Louis, MO, USA), obstructive lung disease is also the predominant indication (fig. 1). There are a number of reasons why emphysema is the most frequent end-stage lung disease in which transplantation is employed. First, emphysema is a very common condition and a frequent cause of mortality. In addition, patients with emphysema who meet criteria for lung transplantation and receive maximal medical therapy, supplemental oxygen and pulmonary rehabilitation survive for a long time on the transplant waiting list. As a result, in the USA, where priority for donor lungs among potential recipients is assigned on the basis of 


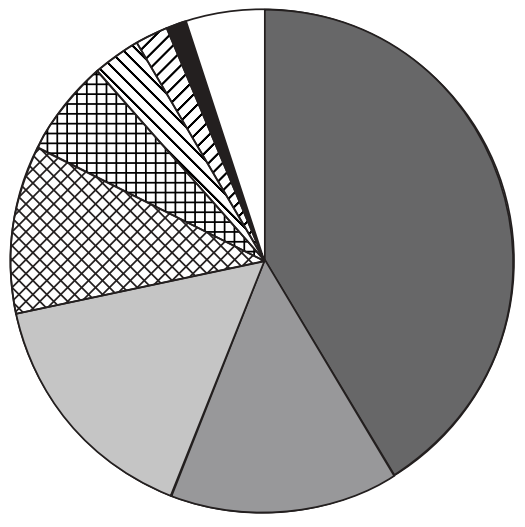

Fig. 1.- Indications for lung transplantation at Barnes-Jewish Hospital (St Louis, MO, USA), 1988-2002. ॠ: chronic obstructive pulmonary disease; : $\alpha_{1}$-antitrypsin deficiency emphysema; :

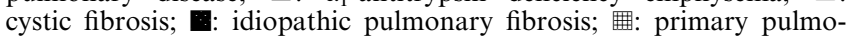

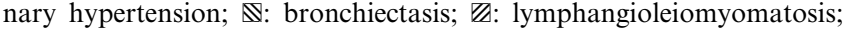
口: retransplantation; $\square$ : others.

waiting time alone, emphysema patients experience an inherent advantage on the waiting list in comparison to patients with cystic fibrosis or pulmonary fibrosis who may have more rapidly progressive disease and a higher likelihood of death while on the waiting list. Efforts are currently under way to create a system for recipient waiting list priority in the USA, which takes into account disease severity and risk of death while on the waiting list as well as risk of death following transplant, so as to assign the highest priority to those potential recipients who are at high risk of waiting list mortality and yet have a high likelihood of undergoing successful lung transplantation (E.P. Trulock, Barnes-Jewish Hospital, personal communication). Such an allocation scheme would rely on complex computer modelling and require frequent national and programmatic updates, not to mention oversight to ensure compliance. Whether such a system is practical or superior to the current one remains to be seen. Perhaps the best allocation system is one which permits the transplant centre to perform a transplant on the patient it judges to have the highest medical priority when a suitable donor becomes available. Such a system is currently in place in the UK, where there are a restricted number of lung transplant programmes [17]. In these centres, the frequency of transplantation for emphysema is much lower and for cystic fibrosis and pulmonary fibrosis much higher than in most busy US lung transplant programmes.

In the paediatric population, cystic fibrosis and pulmonary vascular disease are the prime indications [18]. In addition, there is an interesting group of fibrotic lung diseases which are seen even in the infant age group. The application of lung transplantation to this very young group of patients is one of the exciting recent developments in lung transplantation [19].

\section{Current availability of donor lungs}

Standard criteria for donor lung suitability have not changed much since the early 1990s. Donors with a nonsmoking history, clear chest radiograph, negative bronchoscopy and good gas exchange (arterial oxygen tension $\left(\mathrm{Pa}, \mathrm{O}_{2}\right)$ /inspiratory oxygen fraction $\left.\left(\mathrm{FI}, \mathrm{O}_{2}\right)>300\right)$ are considered ideal. Unfortunately, only $5-10 \%$ of multiorgan donors have lungs that meet these criteria [20]. Brain death is often associated with a variety of pulmonary pathologies: atelectasis, contusion, aspiration, pneumonia, and pulmonary oedema.
A number of strategies have evolved in an effort to deal with the problem of inadequate donor supply. Frequently, what seems to be a marginal donor can be made quite acceptable [21]. Although a significant smoking history $(\geqslant 30$ pack-yrs) in the donor is concerning, it is not an absolute contraindication to the use of otherwise suitable donor lungs. A positive donor Gram stain does not appear to predict posttransplant outcome and its role in donor evaluation has been diminished [22]. Fluid overload is common in prospective donors. Administration of diuretic can significantly improve gas exchange. Atelectasis is a common finding among potential donors. Fibreoptic bronchoscopy enables aspiration of obstructing secretions and improvement in gas exchange. Sometimes alteration of ventilator settings improves the situation. In trauma victims, not all chest radiographic abnormalities are due to pulmonary parenchymal injury. Overlying chest wall contusion can sometimes obscure what is a perfectly acceptable donor lung. Minor pulmonary contusion should not preclude use of donor lungs. The present authors have relaxed their previously strict donor criteria and made increasing use of "marginal" donor lungs (fig. 2) [23]. Of course, these lungs are not used in complicated transplant procedures; rather they are utilised in more straightforward
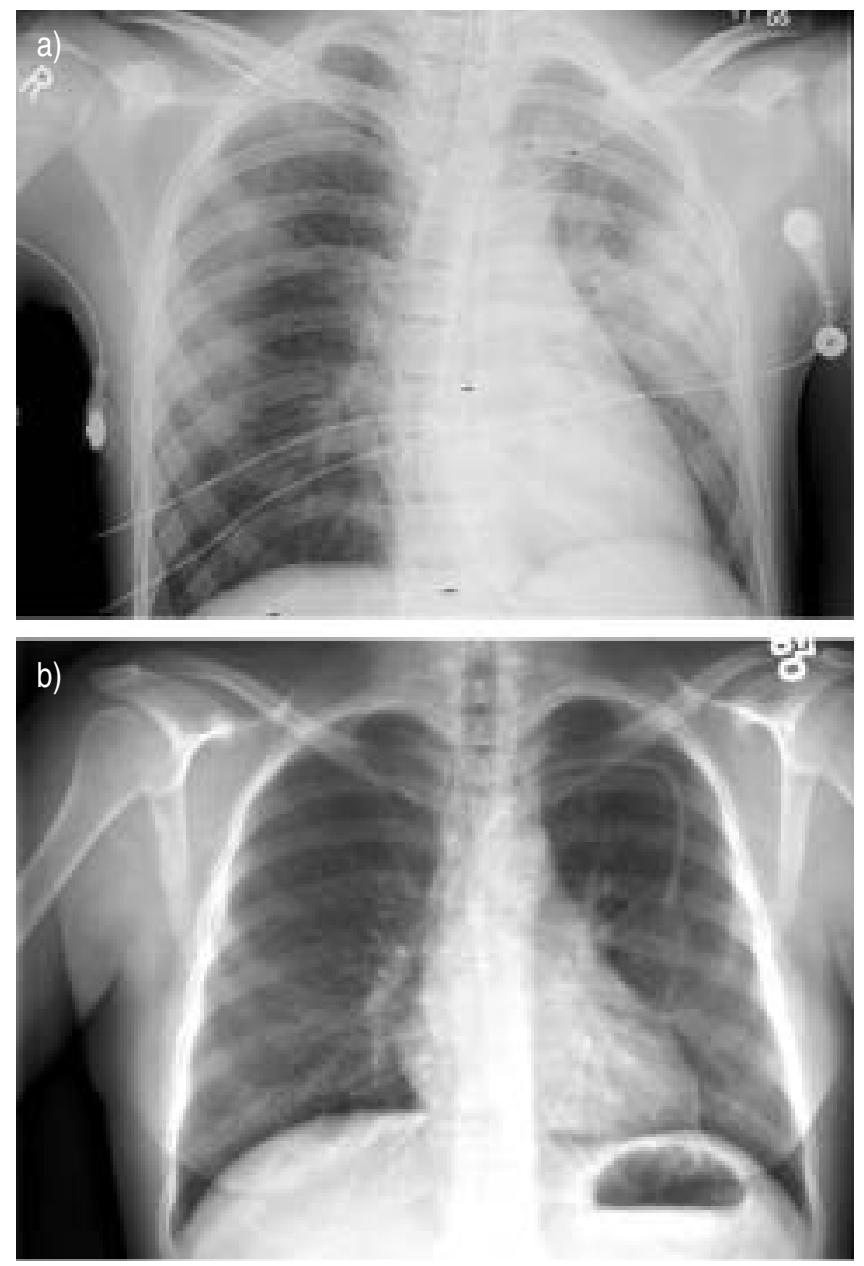

Fig. 2.-a) Chest radiograph of a marginal donor with a moderatesized left pulmonary contusion and mild pulmonary oedema. The donor lungs exhibited good gas exchange and no other contraindications to use. b) Bilateral lung transplant recipient with cystic fibrosis who received these donor lungs of normal chest radiographic appearance. This patient showed excellent lung function with a forced expiratory volume in one second of $112 \%$ of the predicted value at the 3-month follow-up visit. 
cases such as emphysema. In addition, a marginal donor would not be used for a single lung transplant. It has been demonstrated that such selective use of marginal lungs does not impact on early or late results [3]. Most of the present authors' donor harvests are conducted at distant sites. Approximately $20 \%$ of these donor harvests are conducted by another team and the lungs transported for implantation. Interestingly, in the present authors' experience, neither ischaemic time nor harvest by another team influenced early or late results [3]. ABO incompatibility between donor and recipient, human immunodeficiency virus positivity, active malignancies (outside the central nervous system), and active hepatitis infections remain absolute contraindications to donor lung procurement. Older donor age ( $>60 \mathrm{yrs})$ is considered a significant risk factor for adverse outcome after pulmonary transplantation, and, in general, donors aged $<55$ yrs are preferable [2].

The concept of living lobar transplantation is an interesting one. The procedure involves harvesting a left lower lobe from one healthy donor and a right lower lobe from a second donor. Both lobes are implanted as bilateral grafts into a single recipient. This strategy was pioneered by the University of Southern California programme [24]. They have reported impressive results in both adults and children [25]. Furthermore, since paediatric patients receiving living lobar transplants experienced less BOS and better pulmonary function than paediatric recipients receiving cadaveric donor lungs, this group believes living lobar transplantation is the preferred method for children [25]. Living lobar transplantation has also been conducted in other centres; however, the success of the University of Southern California programme has been difficult to duplicate. Thus far, there have been no reports of donor fatality, but a significant number of complications have been encountered [26].

Two novel techniques for the optimisation of donor lung usage have recently been introduced. In the first, a split lung technique that bipartitions a large left donor lung into its two lobes, the upper lobe is transplanted into the recipient's right hemithorax and the lower lobe into the left hemithorax [27]. The second technique involves the use of nonheartbeating donors [28]. Unfortunately, neither of these has the potential to substantially increase the number of available lungs. Xenotransplantation is one solution to overcoming the donor shortage, with the potential for unlimited supply. Unfortunately, advances in this area have been hindered not only by the severe immune response of the recipient but also by apparent incompatibilities between the coagulation systems of different species [29]. It has, therefore, remained relegated to the research realm.

\section{Choice of procedure}

Single lung transplantation is an excellent option in pulmonary fibrosis [30]. The first successful isolated lung transplants were single lung transplants for pulmonary fibrosis $[1,31]$. Selected patients with emphysema, specifically those of shorter stature and older age, can also expect good results from single lung transplantation. Single lung transplantation has been found to be an acceptable option for patients with pulmonary hypertension [32]. However, these can be challenging cases during the first few postoperative days [33]. As a result, some programmes prefer to use bilateral lung transplantation or even combined heart/lung transplantation for patients with pulmonary hypertension. Bilateral transplantation is mandatory for patients with cystic fibrosis and bronchiectasis since both septic native lungs must be excised.
The present authors' programme favours the bilateral transplant option for all disease categories for a number of reasons. In their experience in more than 300 patients undergoing transplantation for obstructive lung disease, bilateral lung transplantation provides superior results [34]. In the present authors' overall transplant experience, late survival is superior in bilateral recipients (fig. 3). In addition, they believe that early postoperative management is made much simpler in the presence of two lung grafts. Bilateral transplantation is also the preferred option among paediatric recipients. In the adult population, bilateral transplantation can be readily conducted through bilateral anterolateral thoracotomy. It is not usually necessary to divide the sternum [35].

Most adult lung transplants can be conducted without the requirement for cardiopulmonary bypass. There are a number of specific indications for institution of cardiopulmonary bypass. Patients with severe primary or secondary pulmonary hypertension most safely undergo transplantation with bypass. Occasionally, patients with cystic fibrosis have such voluminous purulent secretions that independent lung ventilation is impossible. In the present authors' programme, the most frequent indication for bypass is dysfunction (due to early reperfusion injury) of the first implanted lung. In the paediatric age group, cardiopulmonary bypass is usually required since the small airway size in children precludes placement of a double-lumen endotracheal tube for independent lung ventilation [18].

\section{Results}

Operative mortality and long-term survival vary by diagnosis, with emphysema providing results somewhat superior to the more challenging conditions such as pulmonary fibrosis and pulmonary hypertension. Among 689 adult lung transplants performed at Barnes-Jewish Hospital, the operative mortality was $6 \%$.

Postoperative functional results are excellent. In the present authors' programme, following bilateral transplantation for emphysema, the mean forced expiratory volume in one second (FEV1) increased from a preoperative level of $16 \%$ of the predicted value to $84 \%$ pred at 3 months. This improvement in pulmonary function was maintained at $1 \mathrm{yr}$ with a mean FEV1 of $75 \%$ pred [36]. Among cystic fibrosis patients, results are similar, with a preoperative FEV1 of $22 \%$ pred increasing to $68 \%$ pred early postoperatively and $70 \%$

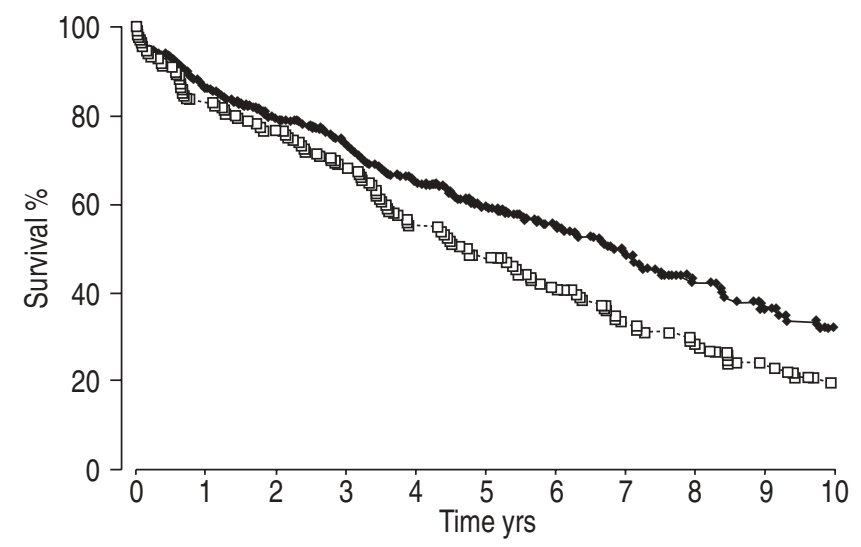

Fig. 3. - Actuarial survival of bilateral ( $\diamond$; $=477)$ versus single ( $\square$; $\mathrm{n}=171$ ) lung transplantation at Barnes-Jewish Hospital (St Louis, MO, USA), 1988-2002. 
pred at 2 yrs [37]. Functional results in patients surviving beyond 5 yrs have been reported by the Toronto group [38]. In this report 5-, 6- and 7-yr actuarial survival was 44, 34 and $29 \%$. Among single lung recipients, FEV1 at 5, 6 and 7 yrs after transplantation was 75,73 and $68 \%$ pred respectively. Although these values are quite good, many recipients with the greatest decline in pulmonary function due to BOS have died and thus are not considered. Experience with pulmonary hypertension has also been gratifying. These patients have experienced immediate restoration of normal right heart function and pulmonary haemodynamics which persists over a 4-yr follow-up period [32]. Overall survival in the present authors' adult transplant recipients is $85 \%$ at $1 \mathrm{yr}$ and $55 \%$ at 5 yrs.

Two hundred and sixty-five paediatric transplants have been performed at the present authors' institutions (St Louis Children's Hospital Lung Transplant Registry; C.B. Huddleston, St Louis Children's Hospital, St Louis, MO, USA, personal communication). The mean age of recipients at the time of transplantation is $9.5 \pm 5.9$ yrs [18]. Actuarial survival of paediatric recipients at the present authors' centre is $77 \%$ at $1 \mathrm{yr}, 62 \%$ at $3 \mathrm{yrs}$ and $55 \%$ at 5 yrs [18].

Among $>14,500$ lung transplant recipients on the ISHLT Registry, overall 1-, 3- and 5-yr survival is 76, 57 and $43 \%$ respectively [2]. Bilateral recipients show superior survival in comparison to their single lung counterparts. In ISHLT Registry experience, there is a significant difference in survival by transplant indication. Patients undergoing lung transplantation for pulmonary fibrosis exhibit a much worse long-term survival than those with cystic fibrosis [2].

Recent studies have shown a survival benefit for lung transplantation due to emphysema in addition to idiopathic pulmonary fibrosis, cystic fibrosis and pulmonary hypertension [12, 14]. The benefit of lung transplantation in patients with congenital heart disease has been questioned $[12,14]$. Many studies have addressed quality of life in lung transplant recipients $[4-6,8,9]$. Improvement in quality of life is seen after the transplant and usually becomes evident after 3-6 months. Mobility, energy, sleep, activities of daily living dependency level and dyspnoea were reported to be improved following lung transplantation [9]. Pretransplant psychological status appears to affect post-transplant quality of life and adjustment [5]. PARIS et al. [39] evaluated the return to work after lung transplantation and reported 22\% employed, $38 \%$ unemployed but medically able to work, $29 \%$ disabled and $10 \%$ retired.

\section{Complications}

\section{Reperfusion injury}

Early lung allograft dysfunction occurs in 15-20\% of cases [40]. Reperfusion injury represents the most frequent cause of early mortality and prolonged intensive care unit stay. A variety of factors such as poor preservation, prolonged ischaemic time or unsuspected donor lung pathology such as contusion or aspiration play a role in its development. The condition is characterised by noncardiogenic pulmonary oedema and progressive lung injury over the first few hours following implantation. The process can progress to severe diffuse alveolar damage requiring maximal ventilatory support and even institution of extracorporeal membrane oxygenation (ECMO). Fortunately, severe reperfusion injury has not been so commonly encountered since the late 1990s. Superior strategies of lung preservation have evolved [41]. It is clear from experimental [42, 43] and clinical [44] work that low-potassium dextran solution provides superior preservation over the high-potassium preservation solutions previously in use. In addition, experimental work suggests that nitric oxide added to the flush solution or inhaled at the time of harvest provides a preservation advantage $[45,46]$. Combination of an antegrade and a retrograde [47, 48] pulmonary vascular flush achieves more uniform distribution of flush solution and superior graft cooling. Lung hyperinflation is an excellent model of pulmonary oedema. Therefore, the present authors are particularly careful to avoid lung hyperinflation during harvest and storage of the donor lungs. Each of these factors has contributed to a reduction in the frequency of reperfusion injury.

Recently, the use of controlled reperfusion in combination with leukocyte depletion has shown promise as a preventative strategy [49-55]. Lick et al. [56] reported a nonrandomised small series in humans utilising this technique with no reperfusion injury. At the time of reperfusion, leukocytefiltered modified perfusate is pumped at a controlled rate $\left(200 \mathrm{~mL} \cdot \mathrm{min}^{-1}\right)$ and pressure $(<20 \mathrm{~mm} \cdot \mathrm{Hg})$ through the transplanted lung for $10 \mathrm{~min}$. The lung is ventilated with a $50 \%$ inspiratory oxygen concentration during the period.

Treatment of ischaemic/reperfusion injury includes diuresis and maximal ventilatory support. In most cases, the reperfusion injury resolves over $24-48 \mathrm{~h}$. It has previously been demonstrated that inhaled nitric oxide is of benefit in severe reperfusion injury as it significantly decreases pulmonary artery pressure and improves the $\mathrm{Pa}, \mathrm{O}_{2} / \mathrm{FI}, \mathrm{O}_{2}$ ratio [57]. Recently, inhaled prostacyclin has been investigated and shown promise as an alternative to nitric oxide [58]. In severe cases, ECMO is a suitable treatment option if employed early [59]. Initiating use of ECMO $>24 \mathrm{~h}$ after injury has been uniformly unsuccessful.

\section{Airway complications}

Bronchial anastomotic complications, which plagued the early lung transplant experience, are no longer common. Improvements in lung preservation, surgical technique and perioperative management of the recipient have reduced the frequency of this complication. In recent experience, the incidence of airway complications was only $4 \%$ [60]. These problems can usually be managed by conservative airway debridement. It is remarkable how a significant area of donor airway necrosis and dehiscence often spontaneously heals and provides a satisfactory result. A variety of airway stents are available for persistent malacic or fibrous strictures [61, 62]. Fatality is rare.

\section{Infections}

Bacterial infections are most common during the early post-transplant period and remain the primary cause of mortality during this period [63]. The most common organisms involved are those colonising the donor or recipient, or those known to populate individual institutions' intensive care units. Analysis of trends in individual hospital's bacterial susceptibilities should guide selection of empirical therapy with adjustments as necessary when sensitivity data are available.

Cytomegalovirus (CMV) disease is the most commonly seen infectious postoperative complication, reportedly affecting $13-75 \%$ of transplant patients, depending on definitions of CMV disease and use of CMV prophylaxis (fig. 4) [64, 65]. Lung transplant recipients who are CMV-negative and receive CMV-positive donor lungs are at the greatest risk of developing severe life-threatening disease from primary infection, whereas it is not usually seen in donor-negative/ recipient-negative transplants [64]. In these high-risk patients, 

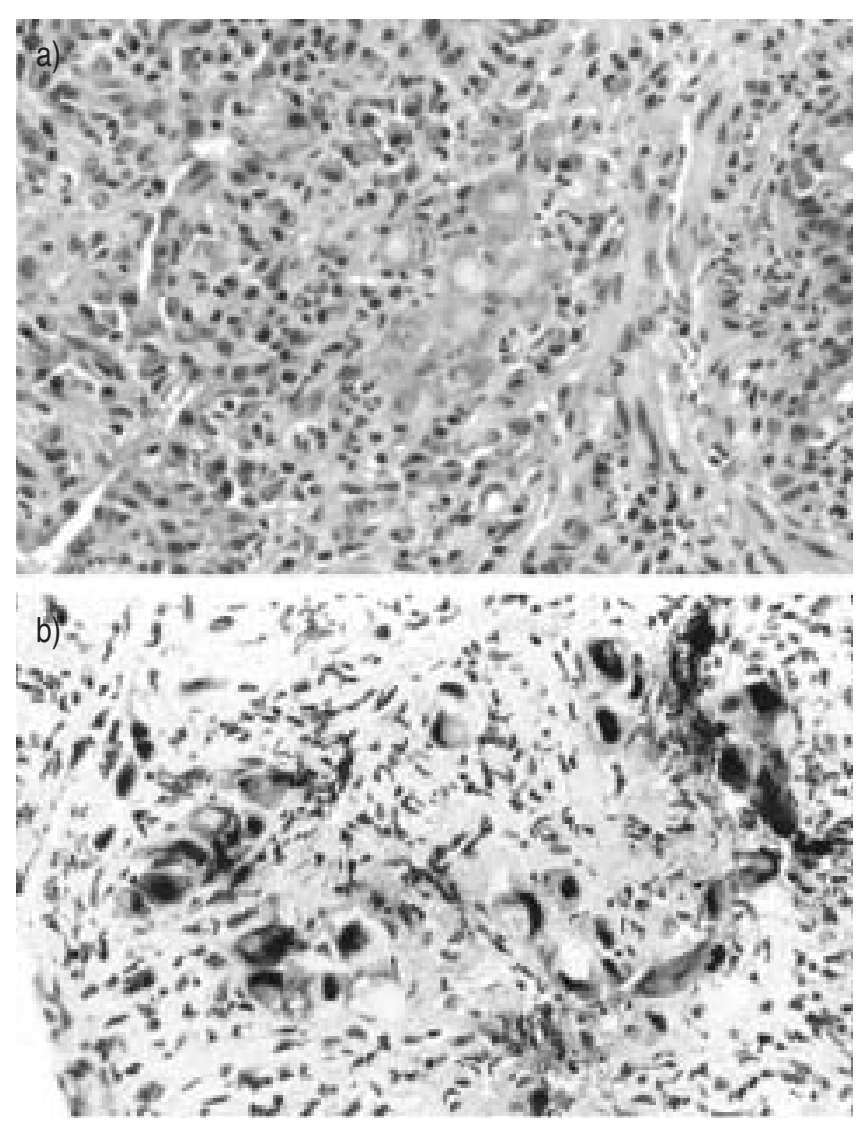

Fig. 4.-a) Transbronchial lung biopsy showing cytomegalovirus (CMV) pneumonitis with demonstration of CMV inclusion bodies. (Haematoxylin and eosin stain). b) Demonstration of CMV inclusion bodies. (Immunoperoxidase stain).

the present authors routinely administer prophylactic treatment consisting of 12 weeks of intravenous ganciclovir $\left(5 \mathrm{mg} \cdot \mathrm{kg}\right.$ body weight ${ }^{-1}$ daily), usually starting 7-14 days after transplantation. They also use CMV-negative or leukocyte-reduced blood products [64]. For CMV infections, the present authors give 14-21 days of intravenous ganciclovir $\left(5 \mathrm{mg} \cdot \mathrm{kg}\right.$ body weight ${ }^{-1}$ b.i.d.). The dose should be adjusted for leukopenia and renal dysfunction. For prevention of relapsing infection, the present authors have recently started using valganciclovir, an oral ganciclovir derivative with increased bioavailability.

Fungal infections are a major problem after lung transplantation and occur early and late following transplantation. Candida albicans is commonly isolated after transplantation and usually represents colonisation [63], but may also be invasive [66]. Aspergillus species can also represent colonisation, but, usually, the presence of these organisms is more serious. In patients with a single lung transplant, one potential reservoir of persistent Aspergillus is the native lung [63]. Treatment is based on infection. Amphotericin is generally the drug of choice for Aspergillus. Candidal infections can be treated with a combination of systemic and inhaled amphotericin and fluconazole (some species are resistant). Prolonged therapy is required for all fungal infections.

\section{Rejection}

Acute allograft rejection is one of the most common complications following lung transplantation. Most recipients experience at least one episode of acute rejection within the first year following the transplant [67, 68]. In 1990, the Lung Rejection Study Group developed a system to characterise lung allograft rejection based on histological criteria found on biopsy, with emphasis on perivascular and interstitial infiltration of mononuclear cells. Note is also made of the coexistence of airway inflammation [69]. Modest revisions of this system were described in 1995 [70]. Since the late 1990s, airway-centred inflammation (lymphocytic bronchitis/bronchiolitis) has been associated with subsequent development of chronic lung allograft dysfunction characterised by the pathological lesion of bronchiolitis obliterans [71]. In addition, it is clear that there is an association between frequency and severity of acute rejection episodes and subsequent development of bronchiolitis obliterans [71]. Thus early detection of acute rejection and alteration of immunosuppression to deal with this problem may have significant impact in the subsequent reduction of chronic lung allograft dysfunction.

In the early lung transplant experience, clinical parameters were often used to establish a clinical diagnosis of acute rejection. Unfortunately, dyspnoea, low-grade fever, perihilar infiltrates, leukocytosis, hypoxia and response to intravenous bolus doses of corticosteroid are rather nonspecific findings. Pathological assessment of multiple transbronchial biopsy specimens has proven to be the "gold" standard for the diagnosis of acute lung allograft rejection [69, 72, 73]. Indeed many programmes, including that of the present authors, have adopted a programme of prophylactic surveillance transbronchial biopsy [68, 72, 74-77]. However, this strategy is controversial and has been abandoned by a number of active lung transplant programmes [78, 79].

Since acute rejection is a predictor of BOS, induction and maintenance immunosuppression regimens as well as treatment strategies for documented acute rejection are subjects of intense interest. Induction therapy with either a cytolytic agent or an interleukin-2 receptor blocker has been shown to reduce early rejection rates [80]. Owing to the ease of administration, fewer side effects, similar efficacy and potentially fewer secondary infections, interleukin-2 receptor blockers are becoming the agents of choice for centres adhering to an induction protocol.

The optimal maintenance immunosuppressive regimen is unclear. Calcineurin inhibitors are used in virtually all patients, with $60 \%$ of patients receiving cyclosporin (Neoral; Novartis Pharmaceutical Corp, East Hanover, NJ, USA; Gengraf; Abbott Laboratories, North Chicago, IL, USA; and Sandimmune; Novartis Pharmaceutical Corp) and 40\% tacrolimus (FK506 and Prograf; Fujisawa Healthcare, Inc., Deerfield, IL, USA) during the first year [2]. During the same period, $>50 \%$ of patients receive azathioprine (Imuran; DSM Pharmaceuticals, Inc., Greenville, NC, USA) and $40 \%$ of patients are on a mycophenolate mofetil (Cellcept; Roche Laboratories, Nutley, NJ, USA) regimen [2]. A frequent first adjustment from maintenance cyclosporin is a switch to tacrolimus in the event of cyclosporin toxicity or acute rejection episodes despite adequate cyclosporin dosage [81, 82]. The role of newer agents such as sirolimus or rapamycin (Rapamune; Wyeth Laboratories, Philadelphia, PA, USA) and a rapamycin derivative called everolimus (Certican; Novartis Pharmaceutical Corp) or leflunomide (Arava; Aventis Pharmaceutical, Inc., Kansas City, MO, USA), a pyrimidine synthesis inhibitor, is evolving in lung transplantation based on success in other solid organ transplants [83-86].

Treatment of acute rejection episodes has two basic goals: 1) to deal with the acute problem; and 2) to reduce the likelihood of further episodes. Conventional therapy has been intravenous methylprednisolone at a dose of $10-15 \mathrm{mg} \cdot \mathrm{kg}$ 
body weight ${ }^{-1}$ for 3-5 days [15]. Although resolution of perivascular infiltrates is often accomplished using this strategy, airway-centred inflammation has been more refractory to therapy. Depending on the maintenance steroid dose, 2-3 weeks of an oral steroid taper is usually prescribed. As acute therapy is initiated, the maintenance immunosuppression regimen should be scrutinised. Low calcineurin inhibitor drug levels warrant investigation, especially for new medications activating the cytochrome $\mathrm{P}_{450}$ enzyme pathway and enhancing calcineurin inhibitor metabolism (e.g. dilantin, rifampicin and nafcillin) [87].

\section{Bronchiolitis obliterans syndrome}

Chronic lung allograft rejection represents the single biggest obstacle to the long-term success of lung transplantation. The pathological lesion is bronchiolitis obliterans (fig. 5). The descriptive term "bronchiolitis obliterans syndrome" has been used to describe a late decline in FEV1 from the postoperative baseline which is not attributable to acute rejection, infection or mechanical obstruction due to a bronchial anastomotic complication. A working formulation was created to characterise and grade BOS [88] and has been revised recently by the ISHLT [89].

BOS is a very common condition following lung transplantation [2]. Most observers believe that every recipient develops some degree of BOS with time during long-term follow-up. In the present authors' programme, actuarial freedom from BOS at 1,3 and 5 yrs after transplantation occurs in 82,42 and $25 \%$ of cases respectively [3].

The cause or causes of BOS are not clear. Evidence suggests that both alloimmune and nonalloimmune mechanisms are important [90]. It is accepted that recipients who have more frequent and severe episodes of acute allograft rejection are more likely to develop subsequent BOS [71]. However, nonimmune mechanisms may also be important. The Duke University transplant programme has made some interesting observations [91-93]. Lung transplant recipients appear to have a high incidence of gastro-oesophageal reflux disease (GORD). In their experience, patients without GORD show a much lower incidence of BOS than those who have uncorrected GORD. They also noted improvement of BOS in recipients with GORD who underwent fundoplication [93]. It has been demonstrated that recipients of lungs from donors dying as a result of nontraumatic brain injury exhibit a lower incidence of BOS than do recipients receiving lungs from donors who die as a result of traumatic brain injury [94].

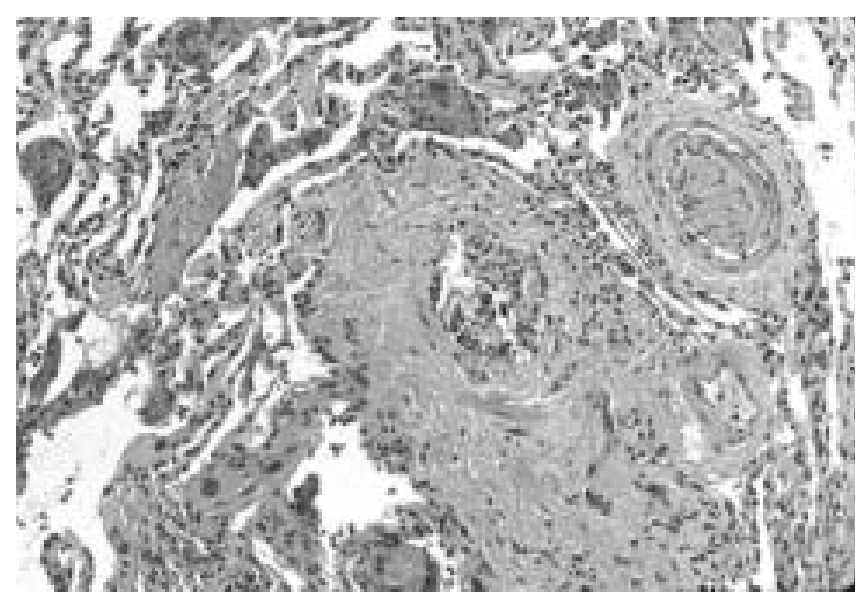

Fig. 5. - Transbronchial lung biopsy showing bronchiolitis obliterans. (Haematoxylin and eosin stain).
Interestingly, for patients undergoing transplantation due to emphysema, bilateral recipients showed a greater freedom from BOS at 5 yrs than their single lung counterparts (53 versus $31 \%$ ) [34]. This was also seen by the Duke University group [95].

Until there is a better understanding of the molecular and cellular mechanisms of bronchiolitis obliterans syndrome, not much progress is likely to be made in its treatment. This goal is hampered by the lack of a suitable experimental model of the bronchiolitis obliterans lesion. A definitive solution for chronic allograft rejection may come in the future through the development of strategies to promote immune tolerance, or permanent acceptance of the graft by the recipient without the need for immunosuppression.

\section{References}

1. Toronto Lung Transplantation Group. Unilateral lung transplantation for pulmonary fibrosis. $N$ Engl $J$ Med 1986; 314: 1140-1145.

2. Hertz MI, Taylor DO, Trulock EP, et al. The Registry of the International Society for Heart and Lung Transplantation: nineteenth official report - 2002. J Heart Lung Transplant 2002; 21: 950-970.

3. Meyers BF, Lynch J, Trulock EP, Guthrie TJ, Cooper JD, Patterson GA. Lung transplantation: a decade of experience. Ann Surg 1999; 230: 362-370 (discussion 370-371).

4. Ramsey SD, Patrick DL, Lewis S, Albert RK, Raghu G. Improvement in quality of life after lung transplantation: a preliminary study. The University of Washington Medical Center Lung Transplant Study Group. J Heart Lung Transplant 1995; 14: 870-877.

5. Cohen L, Littlefield C, Kelly P, Maurer J, Abbey S. Predictors of quality of life and adjustment after lung transplantation. Chest 1998; 113: 633-644.

6. Limbos MM, Chan CK, Kesten S. Quality of life in female lung transplant candidates and recipients. Chest 1997; 112: $1165-1174$.

7. Limbos MM, Joyce DP, Chan CK, Kesten S. Psychological functioning and quality of life in lung transplant candidates and recipients. Chest 2000; 118: 408-416.

8. Gross CR, Raghu G. The cost of lung transplantation and the quality of life post-transplant. Clin Chest Med 1997; 18: 391-403.

9. TenVergert EM, Essink-Bot M-L, Geertsma A, van Enckevort PJ, de Boer WJ, van der Bij W. The effect of lung transplantation on health-related quality of life: a longitudinal study. Chest 1998; 113: 358-364.

10. TenVergert EM, Vermeulen KM, Geertsma A, et al. Quality of life before and after lung transplantation in patients with emphysema versus other indications. Psychol Rep 2001; 89: 707-717.

11. Egan TM, Bennett LE, Garrity ER, et al. Predictors of death on the UNOS lung transplant waiting list: results of a multivariate analysis. $J$ Heart Lung Transplant 2001; 20: 242A.

12. De Meester J, Smits JM, Persijn GG, Haverich A. Listing for lung transplantation: life expectancy and transplant effect, stratified by type of end-stage lung disease, the Eurotransplant experience. J Heart Lung Transplant 2001; 20: 518-524.

13. Hosenpud JD, Bennett LE, Keck BM, Edwards EB, Novick RJ. Effect of diagnosis on survival benefit of lung transplantation for end-stage lung disease. Lancet 1998; 351: 24-27.

14. Charman SC, Sharples LD, McNeil KD, Wallwork J. Assessment of survival benefit after lung transplantation by patient diagnosis. J Heart Lung Transplant 2002; 21: 226-232.

15. Trulock EP. Lung transplantation. Am J Respir Crit Care Med 1997; 155: 789-818.

16. McLaughlin VV, Genthner DE, Panella MM, Rich S. Reduction in pulmonary vascular resistance with long-term 
epoprostenol (prostacyclin) therapy in primary pulmonary hypertension. N Engl J Med 1998; 338: 273-277.

17. National Health Service. Cardiothoracic organ sharing principles. http://www.uktransplant.org.uk/about_transplants/ organ_allocation/cardiothoracic/cardiothoracic_organ_sharing_principles/cardiothoracic_organ_sharing_principles.htm Date updated: 19 July 2003.

18. Huddleston CB, Bloch JB, Sweet SC, de la Morena M, Patterson GA, Mendeloff EN. Lung transplantation in children. Ann Surg 2002; 236: 270-276.

19. Huddleston CB, Mendeloff EN. Lung transplantation in infants. Semin Thorac Cardiovasc Surg Pediatr Card Surg Аnnu 2001; 4: 115-122.

20. Sundaresan S, Trachiotis GD, Aoe M, Patterson GA, Cooper JD. Donor lung procurement: assessment and operative technique. Ann Thorac Surg 1993; 56: 1409-1413.

21. Straznicka M, Follette DM, Eisner MD, Roberts PF, Menza RL, Babcock WD. Aggressive management of lung donors classified as unacceptable: excellent recipient survival one year after transplantation. J Thorac Cardiovasc Surg 2002; 124: 250-258.

22. Weill D, Dey GC, Hicks RA, et al. A positive donor Gram stain does not predict outcome following lung transplantation. J Heart Lung Transplant 2002; 21: 555-558.

23. Sundaresan S, Semenkovich J, Ochoa L, et al. Successful outcome of lung transplantation is not compromised by the use of marginal donor lungs. J Thorac Cardiovasc Surg 1995; 109: 1075-1080.

24. Cohen RG, Barr ML, Schenkel FA, DeMeester TR, Wells WJ, Starnes VA. Living-related donor lobectomy for bilateral lobar transplantation in patients with cystic fibrosis. Ann Thorac Surg 1994; 57: 1423-1428.

25. Starnes VA, Woo MS, MacLaughlin EF, et al. Comparison of outcomes between living donor and cadaveric lung transplantation in children. Ann Thorac Surg 1999; 68: 2279-2283 (discussion 2283-2284).

26. Battafarano RJ, Anderson RC, Meyers BF, et al. Perioperative complications after living donor lobectomy. J Thorac Cardiovasc Surg 2000; 120: 909-915.

27. Couetil JA, Tolan MJ, Loulmet DF, et al. Pulmonary bipartitioning and lobar transplantation: a new approach to donor organ shortage. J Thorac Cardiovasc Surg 1997; 113: 529-537.

28. Steen S, Sjoberg T, Pierre L, Liao Q, Eriksson L, Algotsson L. Transplantation of lungs from a non-heart-beating donor. Lancet 2001; 357: 825-829.

29. Gaca JG, Lesher A, Aksoy O, et al. Disseminated intravascular coagulation in association with pig-to-primate pulmonary xenotransplantation. Transplantation 2002; 73: $1717-1723$.

30. Meyers BF, Lynch JP, Trulock EP, Guthrie T, Cooper JD, Patterson GA. Single versus bilateral lung transplantation for idiopathic pulmonary fibrosis: a ten-year institutional experience. J Thorac Cardiovasc Surg 2000; 120: 99-107.

31. Cooper JD, Pearson FG, Patterson GA, et al. Technique of successful lung transplantation in humans. $J$ Thorac Cardiovasc Surg 1987; 93: 173-181.

32. Pasque MK, Trulock EP, Cooper JD, et al. Single lung transplantation for pulmonary hypertension: single institution experience in 34 patients. Circulation 1995; 92: 22522258.

33. Davis RD, Trulock EP, Manley J, et al. Differences in early results after single lung transplantation. Ann Thorac Surg 1994; 58: 1327-1335.

34. Cassivi SD, Meyers BF, Battafarano RJ, et al. Thirteen-year experience in lung transplantation for emphysema. Ann Thorac Surg 2002; 74: 1663-1669 (discussion 1669-1670).

35. Meyers BF, Sundaresan RS, Guthrie T, Cooper JD, Patterson GA. Bilateral sequential lung transplantation without sternal division eliminates posttransplantation sternal complications. J Thorac Cardiovasc Surg 1998; 117: $358-364$.
36. Kaiser LR, Pasque MK, Trulock EP, Low DE, Dresler CM, Cooper JD. Bilateral sequential lung transplantation: the procedure of choice for double-lung replacement. Ann Thorac Surg 1991; 52: 438-446.

37. Mendeloff EN, Huddleston CB, Mallory GB, et al. Pediatric and adult lung transplantation for cystic fibrosis. $J$ Thorac Cardiovasc Surg 1997; 115: 404414.

38. Chaparro C, Scavuzzo M, Winton T, Keshafjee S, Kesten S. Status of lung transplant recipients surviving beyond five years. J Heart Lung Transplant 1997; 16: 511-516.

39. Paris W, Diercks M, Bright J, et al. Return to work after lung transplantation. J Heart Lung Transplant 1998; 17: 430436.

40. Novick RJ, Gehman KE, Ali IS, Lee J. Lung preservation: the importance of endothelial and alveolar type II cell integrity. Ann Thorac Surg 1996; 62: 302-314.

41. Matsuzaki Y, Waddell TK, Puskas JD, et al. Amelioration of post-ischemic lung reperfusion injury by $\mathrm{PGE}_{1}$. Am Rev Respir Dis 1993; 148: 882-889.

42. Keshavjee S, Yamazaki F, Cardoso PF, McRitchie DI, Patterson GA, Cooper JD. A method for safe twelve-hour pulmonary preservation. J Thorac Cardiovasc Surg 1989; 98: 529-534.

43. Maccherini M, Keshavjee SH, Slutsky AS, Patterson GA, Edelson JD. The effect of low-potassium-dextran versus Euro-Collins solution for preservation of isolated type II pneumocytes. Transplantation 1991; 52: 621-626.

44. Fischer S, Matte-Martyn A, De Perrot M, et al. Lowpotassium dextran preservation solution improves lung function after human lung transplantation. $J$ Thorac Cardiovasc Surg 2001; 121: 594-596.

45. Yamashita M, Schmid RA, Ando K, Cooper JD, Patterson GA. Nitroprusside ameliorates lung allograft reperfusion injury. Ann Thorac Surg 1996; 62: 791-797.

46. Fujino S, Nagahiro I, Triantafillou AN, et al. Inhaled nitric oxide at the time of harvest improves early lung allograft function. Ann Thorac Surg 1997; 63: 1383-1390.

47. Chen C, Gallagher RC, Ardery P, Dyckman W, Donahue S, Low HBC. Retrograde flush and cold storage for twenty-two to twenty-five hours lung preservation with and without prostaglandin $\mathrm{E}_{1}$. J Heart Lung Transplant 1997; 16: 658666.

48. Venuta F, Rendina EA, Bufi M, et al. Preimplantation retrograde pneumoplegia in clinical lung transplantation. J Thorac Cardiovasc Surg 1999; 118: 107-114.

49. Halldorsson A, Kronon M, Allen BS, et al. Controlled reperfusion prevents pulmonary injury after 24-hours of lung preservation. Ann Thorac Surg 1998; 66: 877-884 (discussion 884-885).

50. Halldorsson A, Kronon M, Allen BS, et al. Controlled reperfusion after lung ischemia: implications for improved function after lung transplantation. J Thorac Cardiovasc Surg 1998; 115: 415-425.

51. Clark SC, Sudarshan C, Khanna R, Roughan J, Flecknell PA. Controlled reperfusion and pentoxifylline modulates reperfusion injury after single lung transplantation. $J$ Thorac Cardiovasc Surg 1998; 115: 1335-1341.

52. Bhabra MS, Hopkinson DN, Shaw TE, Onwu N, Hooper TL. Controlled reperfusion protects lung grafts during a transient early increase in permeability. Ann Thorac Surg 1998; 65: 187-192.

53. Halldorsson AO, Kronon MT, Allen BS, Rahman S, Wang $\mathrm{T}$. Lowering reperfusion pressure reduces the injury after pulmonary ischemia. Ann Thorac Surg 2000; 69: 198-203 (discussion 204).

54. Clark SC, Sudarshan CD, Dark JH. Controlled perfusion of the transplanted lung. Ann Thorac Surg 2001; 71: 1755-1756.

55. Fiser SM, Kron IL, Long SM, et al. Controlled perfusion decreases reperfusion injury after high-flow reperfusion. J Heart Lung Transplant 2002; 21: 687-691.

56. Lick SD, Brown PS Jr, Kurusz M, Vertrees RA, McQuitty CK, Johnston WE. Technique of controlled reperfusion of 
the transplanted lung in humans. Ann Thorac Surg 2000; 69: 910-912.

57. Date H, Triantafillou A, Trulock E, Cooper J, Patterson G. Inhaled nitric oxide reduces human lung allograft dysfunction. J Thorac Cardiovasc Surg 1996; 111: 913-919.

58. Fiser SM, Cope JT, Kron IL, et al. Aerosolized prostacyclin (epoprostenol) as an alternative to inhaled nitric oxide for patients with reperfusion injury after lung transplantation. J Thorac Cardiovasc Surg 2001; 121: 981-982. (Erratum in J Thorac Cardiovasc Surg 2001; 121: 1136).

59. Meyers BF, Sundt TM 3rd, Henry S, et al. Selective use of extracorporeal membrane oxygenation is warranted after lung transplantation. J Thorac Cardiovasc Surg 2000; 120: 20-26.

60. Date H, Trulock EP, Arcidi JM, Sundaresan S, Cooper JD, Patterson GA. Improved airway healing after lung transplantation: an analysis of 348 bronchial anastomoses. J Thorac Cardiovasc Surg 1995; 110: 1424-1433.

61. Susanto I, Peters JI, Levine SM, Sako EY, Anzueto A, Bryan CL. Use of balloon-expandable metallic stents in the management of bronchial stenosis and bronchomalacia after lung transplantation. Chest 1998; 114: 1330-1335.

62. Chhajed PJ, Malouf MM, Tamm M, Spratt P, Glanville AR. Interventional bronchoscopy for the management of airway complications following lung transplantation. Chest 2001; 120: $1894-1899$.

63. Chaparro C, Kesten S. Infections in lung transplant recipients. Clin Chest Med 1997; 18: 339-351.

64. Ettinger NA, Bailey TC, Trulock EP, et al. Cytomegalovirus infection and pneumonitis. Impact after isolation lung transplantation. Am Rev Respir Dis 1993; 147: 1017-1023.

65. Gutierrez CA, Chaparro C, Drajden M, Winton T, Kesten S. Cytomegalovirus viremia in lung transplant recipients receiving ganciclovir and immune globulin. Chest 1998; 113: 924-932.

66. Kanj SS, Welty-Wolf K, Madden J, et al. Fungal infections in lung and heart-lung transplant recipients. Report of 9 cases and review of the literature. Medicine (Baltimore) 1996; 75: 142-156.

67. Husain AN, Siddiqui MT, Holmes EW, et al. Analysis of risk factors for the development of bronchiolitis obliterans syndrome. Am J Respir Crit Care Med 1999; 159: 829-833.

68. Hopkins PM, Aboyoun CL, Chhajed PN, et al. Prospective analysis of 1,235 transbronchial lung biopsies in lung transplant recipients. J Heart Lung Transplant 2002; 21 : 1062-1067.

69. Berry GJ, Brunt EM, Chamberlain D, et al. A working formulation for the standardization of nomenclature in the diagnosis of heart and lung rejection: Lung Rejection Study Group. J Heart Lung Transplant 1990; 9: 593-601.

70. Yousem SA, Berry GJ, Cagle PT, et al. Revision of the 1990 working formulation for the classification of pulmonary allograft rejection: Lung Rejection Study Group. J Heart Lung Transplant 1996; 15: 1-15.

71. Sharples LD, McNeil K, Stewart S, Wallwork J. Risk factors for bronchiolitis obliterans: a systematic review of recent publications. J Heart Lung Transplant 2002; 21: 271-281.

72. Trulock EP, Ettinger NA, Brunt EM, Pasque MK, Kaiser LR, Cooper JD. The role of transbronchial lung biopsy in the treatment of lung transplant recipients: an analysis of 200 consecutive procedures. Chest 1992; 102: 1049-1054.

73. Higenbottam T, Stewart S, Penketh A, Wallwork J. Transbronchial lung biopsy for the diagnosis of rejection in heart-lung transplant patients. Transplantation 1988; 46: 532-539.

74. Sibley RK. The role of transbronchial biopsies in the management of lung transplant recipients. J Heart Lung Transplant 1993; 12: 308-324.

75. Boehler A, Vogt P, Zollinger A, Weder W, Speich R. Prospective study of the value of transbronchial lung biopsy after lung transplantation. Eur Respir J 1996; 9: 658-662.
76. Guilinger RA, Paradis IL, Dauber JH, et al. The importance of bronchoscopy with transbronchial biopsy and bronchoalveolar lavage in the management of lung transplant recipients. Am J Respir Crit Care Med 1995; 152: 2037-2043.

77. Baz MA, Layish DT, Govert JA, et al. Diagnostic yield of bronchoscopies after isolated lung transplantation. Chest 1996; 110: 84-88.

78. Tamm M, Sharples LD, Higenbottam TW, Stewart S, Wallwork J. Bronchiolitis obliterans syndrome in heartlung transplantation: surveillance biopsies. Am J Respir Crit Care Med 1997; 155: 1705-1710.

79. Valentine VG, Taylor DE, Dhillon GS, et al. Success of lung transplantation without surveillance bronchoscopy. J Heart Lung Transplant 2002; 21: 319-326.

80. Brock MV, Borja MC, Ferber L, et al. Induction therapy in lung transplantation: a prospective, controlled clinical trial comparing OKT3, anti-thymocyte globulin, and daclizumab. J Heart Lung Transplant 2001; 20: 1282-1290.

81. Vitulo P, Oggionni T, Cascina A, et al. Efficacy of tacrolimus rescue therapy in refractory acute rejection after lung transplantation. J Heart Lung Transplant 2002; 21: 435-439.

82. Horning NR, Lynch JP, Sundaresan SR, Patterson GA, Trulock EP. Tacrolimus therapy for persistent or recurrent acute rejection after lung transplantation. J Heart Lung Transplant 1998; 17: 761-767.

83. Kahan BD. Efficacy of sirolimus compared with azathioprine for reduction of acute renal allograft rejection: a randomised multicentre study. The Rapamune US Study Group. Lancet 2000; 356: 194-202.

84. Hong JC, Kahan BD. Sirolimus rescue therapy for refractory rejection in renal transplantation. Transplantation 2001; 71 : 1579-1784.

85. Snell GI, Levvey BJ, Chin W, et al. A role for sirolimus in lung and heart transplant recipients. Transplant Proc 2001; 33: 1084-1085.

86. Williams JW, Mital D, Chong A, et al. Experiences with leflunomide in solid organ transplantation. Transplantation 2002; 73: 358-366.

87. Chakinala MM, Trulock EP. Acute allograft rejection after lung transplantation: diagnosis and therapy. Chest Surg Clin $N$ Am 2003 (in press).

88. Cooper JD, Billingham M, Egan T, et al. A working formulation for the standarization of nomenclature and for clinical staging of chronic dysfunction in lung allografts. International Society for Heart and Lung Transplantation. J Heart Lung Transplant 1993; 12: 713-716.

89. Estenne M, Maurer JR, Boehler A, et al. Bronchiolitis obliterans syndrome 2001: an update of the diagnostic criteria. J Heart Lung Transplant 2002; 21: 297-310.

90. Estenne M, Hertz MI. Bronchiolitis obliterans after human lung transplantation. Am J Respir Crit Care Med 2002; 166: 440-444.

91. Palmer SM, Miralles AP, Howell DN, Brazer SR, Tapson VF, Davis RD. Gastroesophageal reflux as a reversible cause of allograft dysfunction after lung transplantation. Chest 2000; 118: 1214-1217.

92. Lau CL, Palmer SM, Howell DN, et al. Laparoscopic antireflux surgery in the lung transplant population. Surg Endosc 2002; 16: 1674-1678.

93. Davis RD, Lau CL, Eubanks S, Hadjiliadis D, Palmer SM. Improved lung allograft function following fundoplication in lung transplant patients with GERD. $J$ Thorac Cardiovasc Surg 2003; 125: 533-542.

94. Ciccone AM, Stewart KC, Meyers BF, et al. Does donor cause of death affect the outcome of lung transplantation? J Thorac Cardiovasc Surg 2002; 123: 429-434 (discussion 434 436).

95. Hadjiliadis D, Davis RD, Palmer SM. Is transplant operation important in determining posttransplant risk of bronchiolitis obliterans syndrome in lung transplant recipients? Chest 2002; 122: 1168-1175. 